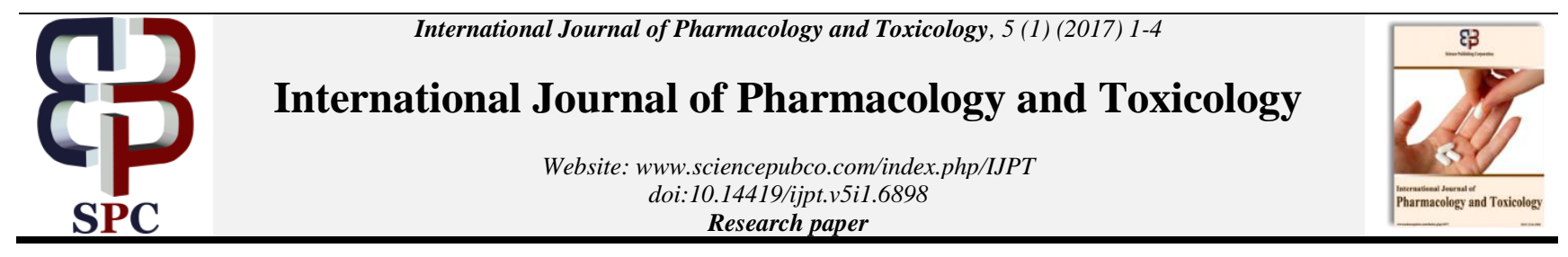

\title{
Antibacterial activity of Saponaria officinalis and Zanthoxylum aramatum
}

\author{
Veda Priya. G ${ }^{1 *}$, MallikarjunaRao ${ }^{2}$, Ganga Rao B ${ }^{3}$ \\ ${ }^{1}$ Research Scholar, A.U College of Pharmaceutical Sciences, Andhra University Visakhapatnam, A.P, India-530 003 \\ ${ }^{2}$ A.U College of Pharmaceutical Sciences, Andhra University Visakhapatnam, A.P, India-530 003 \\ ${ }^{3}$ Professor in Pharmacognosy and Phytochemistry A.U College of Pharmaceutical Sciences, \\ Andhra University Visakhapatnam, A.P, India-530 003 \\ *Corresponding author E-mail:gummadi.veda88@gmail.com
}

\begin{abstract}
The present study was carried out to evaluate the antimicrobial properties of two traditional medicinal plant species Saponaria officinalis and Zanthoxylum aramatum belonging to the families Raryophyllaceae and Rutaceae. The root part was selected for the antibacterial activity, and extracts were prepared using soxhlet extraction procedure using different solvents successively. Different extracts of selected plants tested their anti-microbial property using agar well diffusion method at different concentration on standard human pathogenic bacterial strains. The selected plants extracts concentrated dependent bactericidal activity on tested standard bacterial strains. The zones of inhibitions were measured for each concentration of various extracts on each bacterial strain tested in a millimeter (mm). All concentrations of extracts showed minimum zone of inhibition $(8 \mathrm{~mm})$. The chloroform extracts at $5 \mathrm{mg} / 100 \mu \mathrm{L}$ showed less activity. But, as the concentration increases the bactericidal activity was increased. The extracts showed more activity at $40 \mathrm{mg} / 100 \mu \mathrm{L}$. Among two plants S. officinalis showed more antibacterial activity. In these, methanol extracts of two plants more competent results along with ciprofloxacin on tested bacterial strains. The extracts also showed more activity on gram-negativeorganisms compared to gram-positiveorganisms. The extracts showed more activity on E. coli and S. typhimurium and lower activity on $C$. sporogenes and S. pneumoniae. The results of the present study provide the evidence on antibacterial property of selected medicinal plants and there is a scope to further studies on isolation of antimicrobial compounds from these species.
\end{abstract}

Keywords: Saponaria Officinalis;ZanthoxylumAramatum; Roots and Antimicrobial Activity.

\section{Introduction}

Antibiotics are the drugs used in the treatment of bacterial infections. They may take life or reduce the bacterial growth by different mechanism of actions. The antibiotics play an important role in medicine from early mid of $20^{\text {th }}$ century (Aminov, 2010; Claudi et al., 2010). They help in the treatment of different diseases and almost eradication of some diseases like tuberculosis.However, as time passes the handling of antibiotics in treatments of diseases increased, and the over usage provoked the development of resistance in bacteria (Siang Yong and Yvonne, 2015; Aminov, 2009). The development of resistance in microorganisms against antibiotics outpaced the development of new drugs (Gootz, 1990; Sum et al., 1999; Eliopolus, 2004; Jaswanthrai et al., 2013). The naturally occurring products are the main source for the indentifying and development of new antibiotics (Habich and Von Nussbaum, 2006). These natural occurring compounds are many times starting materials for synthesis of new antibiotics, and they are less toxic. Because, It may be natural products are not suitable for human therapy as their existing forms. However, the identification of natural origin antibiotics is so important against multidrug resistant bacteria. Plants are the best source for different chemical compounds having various bioactive molecules (Schelz et al., 2010; Jatin Srivastava et al., 2014). But, there are more medicinal plants are not identified for their biological activities, including antibiotic activity.In this point of view, we selected the two medic- inal plants, i.e. Saponaria officinalis and Zanthoxylum aramatumfor the present study.

Saponaria officinalis is a perennial plant belongs to caryophyllaceae family, commonly called as soapwort. The different parts of S. officinalis plant has been used in traditional medicine in various diseases like roots as blood purifier, diuretic, diaphoretic, cholagogue; roots and leaves for scrofula and skin diseases; sap for scabies, hepatic eruptions, to increase bile flow and plant for respiratory disorders since ancient times (Khare, 2007; Wolff et al., 2006). The recent studies show it contains different phytochemicals like saponins and suporbic acid.

Zanthoxylum aramatum commonly known as Indian prikly ash belongs to the Rutaceae family. The plants part of the Z aramatum used in medicine as carminative, stomachic and anthelmintic. The fruits and seeds used for fever, scabies, dyspepsia, snake bite remedy, pains rheumatism, cholera and diabetes (Singh and Singh, 2011;Negi et al., 2011; Rajbhandari, 2001).

The selected plants Saponaria officinalis and Zanthoxylum aramatumare using in traditional medicine in the treatment of different illnesses. But, there very less scientific evidence present on their biological activities. So, we selected the roots part of the S. officinalis and $Z$. aramatum for the antimicrobial activity.

\section{Materials and methods}

\subsection{Chemicals and drugs}


The chemicals used in the present study were analytical grade from Merk. The standard drug ciprofloxacin was purchased from Apollo pharmacy (Made Dr. Reddy's).

\subsection{Collection of plant materials and preparation of extracts}

The plant materials Saponaria officinalis (Voucher number: 1221) and Zanthoxylum aramatum(Voucher number: 1765) were collected from Tirupati region, Andhra Pradesh and authenticated by the taxonomist Dr. K. MadhavaChetty, Depart of Botany, Sri Venkateswara University. Freshly collected root plant material was dried under shade, and the dried material was milled to obtain a coarse powder. The powdered material was separately extracted in a Soxhlet apparatus for $6 \mathrm{hrs}$ successively with ethyl acetate, chloroform and methanol successively. Finally, the collected solution through soxhlet extraction was concentrated to dryness under vacuum by using Rota-vapor to get the dry extract and stored in desiccators.

\subsection{Test organisms}

The bacterial species were collected from National collection of industrial micro organisms (NCIM), National chemical Laboratory (NCL), Pune.The Bacterial species were maintained in the nutrient broth medium on placing shaker in separate culture tubes for each species separately. Out of eight, four are Gram-positiveorganisms Clostridium sporogenes (NCIM 5125), Listeria monocytogenes(NCIM 5260), Staphylococcus aureus (NCIM 2127), Streptococcus pneumoniae (NCIM 5281) and four are Gram Negative Escherichia coli (NCIM 2931), Pseudomonas aeruginosa (NCIM 5029), Yersinia enterocolitica (NCIM 5263), Salmonella typhimurium (NCIM 2501)

\subsection{Antibacterial activity}

The selected plants extracts were tested for their antibacterial activity on different pathogenic bacterial strains using agar well diffusion method (Ganga Rao et al., 2012). The concentration extracts were prepared 50, 100, 200 and $400 \mathrm{mg} / \mathrm{ml}$ in Dimethyl sulfoxide (DMSO), finally added $100 \mu 1$ to each well in dried agar plate. The method briefly is; nutrient agar media was prepared and sterilized using an autoclave. After sterilization cooled to room temperature and agar, nutrient medium separated equally as per requirements and each part was inoculated with $200 \mu \mathrm{L}$ of testing bacterial strains in aseptic conditions. After inoculation the agar nutrient medium was transferred to 6" Petri-dishes allowed to solidification. After solidification wells/cups were made with sterile borer $(5 \mathrm{~mm})$. Then, wells/cups were filled with the standard drug, different concentration of extracts and extract vehicle/control (DMSO) and allowed the samples to diffusion into the medium for 30min without disturbing the plates. After diffusion plates were incubated for $24 \mathrm{hrs}$ at $37 \pm 2^{\circ} \mathrm{C}$. After $24 \mathrm{hrs}$, the plates were examined for extracts' antibacterial activity by measuring the zone of inhibitions (in a millimeter (mm)) around the wells/cups. The experiment was done thrice, and results were expressed in mean \pm S.E.M.

\section{Results and discussion}

The selected plants extracts showed different zones of inhibitions of tested bacterial strains, it conforms that they contain antibacterial activity. These results could be important for the researchers working on isolation of natural compounds from medicinal plants. The selected plants extracts concentrated dependent bactericidal activity on tested standard bacterial strains. The results showed in Tables 1 and 2, zones of inhibitions were measured for each concentration of various extracts on each bacterial strain tested in $\mathrm{mm}$. All concentrations of extracts showed a minimum zone of inhibition $(8 \mathrm{~mm})$.

Table 1:Zones of Inhibitions of Different Extracts ofSaponaria officinalis Root Part

\begin{tabular}{|c|c|c|c|c|c|c|c|c|c|}
\hline \multirow{2}{*}{ Name of the extract } & \multirow{2}{*}{ Concentration of extracts $(\mathrm{mg} / 100 \mu \mathrm{L})$} & \multicolumn{8}{|c|}{ Name of the microorganisms } \\
\hline & & C.s & L. $\mathrm{m}$ & S. a & S. p & E. c & P. a & Y.e & S. t \\
\hline \multirow{7}{*}{ Ethyl acetate } & \multirow{2}{*}{5} & $8.33 \pm$ & $7.33 \pm$ & $6.67 \pm$ & $7.00 \pm$ & $8.33 \pm$ & $6.67 \pm$ & $7.67 \pm$ & $9.00 \pm$ \\
\hline & & 0.33 & 0.3 & 0.3 & 0.00 & 0.33 & 0.33 & 0.3 & 0.00 \\
\hline & \multirow{2}{*}{10} & $10.3 \pm$ & $8.67 \pm$ & $9.00 \pm$ & $8.33 \pm$ & $11.33 \pm$ & $9.33 \pm$ & $8.00 \pm$ & $12.00 \pm$ \\
\hline & & 0.33 & 0.33 & 0.00 & 0.33 & 0.33 & 0.33 & 0.00 & 0.00 \\
\hline & \multirow{2}{*}{20} & $12.67 \pm$ & $10.67 \pm$ & $11.33 \pm$ & $10.3 \pm$ & $14.00 \pm$ & $11.33 \pm$ & $10.00 \pm$ & $14.33 \pm$ \\
\hline & & 0.3 & 0.33 & 0.3 & 0.3 & 0.00 & 0.33 & 0.00 & 0.33 \\
\hline & 40 & $15.33 \pm$ & $12.67 \pm$ & $14.00 \pm$ & $12.3 \pm$ & $16.00 \pm$ & $13.67 \pm$ & $13.33 \pm$ & $15.67 \pm$ \\
\hline \multirow{8}{*}{ Chloroform } & \multirow{2}{*}{5} & $6.00 \pm$ & $6.33 \pm$ & $7.33 \pm$ & $7.00 \pm$ & $7.67 \pm$ & $7.33 \pm$ & $7.00 \pm$ & $7.33 \pm$ \\
\hline & & 0.00 & 0.33 & 0.33 & 0.00 & 0.3 & 0.33 & 0.00 & 0.3 \\
\hline & \multirow{2}{*}{10} & $8.33 \pm$ & $8.33 \pm$ & $9.00 \pm$ & $8.67 \pm$ & $9.00 \pm$ & $8.67 \pm$ & $9.00 \pm$ & $9.33 \pm$ \\
\hline & & 0.33 & 0.3 & 0.00 & 0.3 & 0.00 & 0.33 & 0.00 & 0.33 \\
\hline & \multirow{2}{*}{20} & $10.33 \pm$ & $9.67 \pm$ & $11.33 \pm$ & $10.67 \pm$ & $11.33 \pm$ & $10.33 \pm$ & $11.00 \pm$ & $11.67 \pm$ \\
\hline & & 0.33 & 0.33 & 0.33 & 0.33 & 0.33 & 0.33 & 0.58 & 0.33 \\
\hline & \multirow{2}{*}{40} & $12.33 \pm$ & $11.67 \pm$ & $13.67 \pm$ & $13.3 \pm$ & $13.67 \pm$ & $13.33 \pm$ & $13.67 \pm$ & $14.33 \pm$ \\
\hline & & 0.3 & 0.33 & 0.3 & 0.3 & 0.3 & 0.33 & 0.3 & 0.33 \\
\hline \multirow{7}{*}{ Methanol } & 5 & 0.33 & 0.33 & 0.33 & 0.00 & 0.3 & 0.33 & 0.00 & 0.00 \\
\hline & \multirow{2}{*}{10} & $10.33 \pm$ & $9.33 \pm$ & $9.67 \pm$ & $10.67 \pm$ & $11.67 \pm$ & $10.67 \pm$ & $11.67 \pm$ & $11.33 \pm$ \\
\hline & & 0.33 & 0.3 & 0.33 & 0.3 & 0.33 & 0.33 & 0.33 & 0.3 \\
\hline & \multirow{2}{*}{20} & $12.67 \pm$ & $11.00 \pm$ & $11.67 \pm$ & $13.3 \pm$ & $15.67 \pm$ & $13.33 \pm$ & $14.67 \pm$ & $15.33 \pm$ \\
\hline & & 0.3 & 0.00 & 0.3 & 0.33 & 0.3 & 0.33 & 0.3 & 0.33 \\
\hline & \multirow{2}{*}{40} & $15.67 \pm$ & $13.33 \pm$ & $14.33 \pm$ & $16.0 \pm$ & $19.67 \pm$ & $16.33 \pm$ & $17.67 \pm$ & $18.67 \pm$ \\
\hline & & 0.33 & 0.33 & 0.33 & 0.00 & 0.33 & 0.33 & 0.3 & 0.33 \\
\hline \multirow{2}{*}{ Ciprofloxacin } & \multirow{2}{*}{$(100 \mu \mathrm{g} / 100 \mu \mathrm{L})$} & $19.97 \pm$ & $18.67 \pm$ & $23.67 \pm$ & $25.00 \pm$ & $22.33 \pm$ & $21.67 \pm$ & $23.00 \pm$ & $21.33 \pm$ \\
\hline & & 0.09 & 0.33 & 0.33 & 0.58 & 0.33 & 0.33 & 1.00 & 0.67 \\
\hline DMSO & $100 \mu \mathrm{L}$ & - & - & - & - & - & - & - & - \\
\hline
\end{tabular}

C. $\mathrm{s}=$ Clostridium sporogenes $; \mathrm{L} . \mathrm{m}=$ Listeria monocytogenes $; \mathrm{S} . \mathrm{a}=$ Staphylococcus aureus $; \mathrm{S} . \mathrm{p}=$ Streptococcus pneumoniae $;$ E. $\mathrm{c}=$ Escherichia coli $; \mathrm{P}$. $\mathrm{a}=$ Pseudomonas aeruginosa $; \mathrm{Y} . \mathrm{e}=$ Yersinia enterocolitica; $\mathrm{S} . \mathrm{t}=$ Salmonella typhimurium. 
Table 2: Zones of Inhibitions of Different Extracts of Zanthoxylum aramatum Root Part

\begin{tabular}{|c|c|c|c|c|c|c|c|c|c|}
\hline \multirow{2}{*}{ Name of the extract } & \multirow{2}{*}{ Concentration of extracts $(\mathrm{mg} / 100 \mu \mathrm{L})$} & \multicolumn{8}{|c|}{ Name of the microorganisms } \\
\hline & & C.s & L. $\mathrm{m}$ & S. a & S. $p$ & E. c & P. a & Y.e & S. $\mathrm{t}$ \\
\hline \multirow{6}{*}{ Ethyl acetate } & 5 & - & 7 & $\begin{array}{l}8.3 \pm \\
0.3\end{array}$ & - & $\begin{array}{l}8.67 \pm \\
0.33\end{array}$ & $\begin{array}{l}7.67 \pm \\
0.33\end{array}$ & 8 & 9 \\
\hline & 10 & 7 & $\begin{array}{l}8.3 \pm \\
0.33\end{array}$ & $\begin{array}{l}10.3 \pm \\
0.3\end{array}$ & $\begin{array}{l}7.33 \pm \\
0.33\end{array}$ & $\begin{array}{l}10.67 \pm \\
0.33\end{array}$ & $\begin{array}{l}9.67 \pm \\
0.33\end{array}$ & 10 & $\begin{array}{l}11.33 \pm \\
0.00\end{array}$ \\
\hline & & $9.33 \pm$ & $10.67 \pm$ & $13.3 \pm$ & $9.3 \pm$ & $13.67 \pm$ & $12.33 \pm$ & $12.67 \pm$ & $13.67 \pm$ \\
\hline & 20 & 0.3 & 0.33 & 0.3 & 0.3 & 0.3 & 0.33 & 0.3 & 0.33 \\
\hline & & $11.3 \pm$ & $13.67 \pm$ & $15.67 \pm$ & $11.67 \pm$ & $16.67 \pm$ & $14.33 \pm$ & $15 \pm$ & $17.0 \pm$ \\
\hline & 40 & 0.33 & 0.33 & 0.3 & 0.33 & 0.00 & 0.33 & 0.57 & 0.58 \\
\hline \multirow{7}{*}{ Chloroform } & 5 & - & $\begin{array}{l}7.33 \pm \\
0.33\end{array}$ & - & - & $\begin{array}{l}7.67 \pm \\
0.3\end{array}$ & $\begin{array}{l}6.67 \pm \\
0.33\end{array}$ & - & 8 \\
\hline & & $6.67 \pm$ & $8.0 \pm$ & $7.0 \pm$ & $6.33 \pm$ & $9.33 \pm$ & $7.67 \pm$ & $6.33 \pm$ & $9.67 \pm$ \\
\hline & 10 & 0.33 & 0.0 & 0.0 & 0.3 & 0.3 & 0.33 & 0.33 & 0.33 \\
\hline & & $7.67 \pm$ & $9.33 \pm$ & $8.33 \pm$ & $7.33 \pm$ & $10.67 \pm$ & $9.67 \pm$ & $7.67 \pm$ & $11.33 \pm$ \\
\hline & 20 & 0.33 & 0.33 & 0.33 & 0.33 & 0.33 & 0.33 & 0.58 & 0.33 \\
\hline & 40 & $9.0 \pm$ & $11.33 \pm$ & $10.33 \pm$ & $8.67 \pm$ & $12.67 \pm$ & $11.67 \pm$ & $9.67 \pm$ & $13.67 \pm$ \\
\hline & 40 & 0.57 & 0.33 & 0.3 & 0.3 & 0.3 & 0.33 & 0.3 & 0.33 \\
\hline \multirow{7}{*}{ Methanol } & 5 & $7.33 \pm$ & 7 & 8 & $6.67 \pm$ & $7.33 \pm$ & $7.67 \pm$ & $8.33 \pm$ & $8.67 \pm$ \\
\hline & & 0.33 & & & 0.00 & 0.3 & 0.33 & 0.33 & 0.3 \\
\hline & 10 & $9.33 \pm$ & $8.67 \pm$ & $9.67 \pm$ & $9.33 \pm$ & $10.33 \pm$ & $9.67 \pm$ & $10.33 \pm$ & $11.33 \pm$ \\
\hline & & 0.33 & 0.3 & 0.33 & 0.3 & 0.33 & 0.33 & 0.33 & 0.3 \\
\hline & 20 & $11.67 \pm$ & $10.33 \pm$ & $11.67 \pm$ & 11 & $13.33 \pm$ & $12.0 \pm$ & $12.67 \pm$ & $13.67 \pm$ \\
\hline & & 0.57 & 0.33 & 0.3 & & 0.3 & 0.57 & 0.3 & 0.33 \\
\hline & 40 & $13.33 \pm$ & $12.33 \pm$ & $14.0 \pm$ & $13.3 \pm$ & $15.67 \pm$ & $14.33 \pm$ & $15.67 \pm$ & $16.33 \pm$ \\
\hline & & $19.97 \pm$ & $18.67 \pm$ & $23.67 \pm$ & $25.00 \pm$ & $22.33 \pm$ & $21.67 \pm$ & $23.00 \pm$ & $21.33+$ \\
\hline Ciprofloxacin & $(100 \mu \mathrm{g} / 100 \mu \mathrm{L})$ & 0.09 & 0.33 & 0.33 & 0.58 & 0.33 & 0.33 & 1.00 & 0.67 \\
\hline DMSO & $100 \mu \mathrm{L}$ & - & - & - & - & - & - & - & - \\
\hline
\end{tabular}

C. $\mathrm{s}=$ Clostridium sporogenes $; \mathrm{L} . \mathrm{m}=$ Listeria monocytogenes; $\mathrm{S} . \mathrm{a}=$ Staphylococcus aureus $; \mathrm{S} . \mathrm{p}=$ Streptococcus pneumoniae $;$ E. $\mathrm{c}=$ Escherichia coli $;$ P. $\mathrm{a}=$ Pseudomonas aeruginos $a ;$ Y. $\mathrm{e}=$ Yersinia enterocolitica $; \mathrm{S} . \mathrm{t}=$ Salmonella typhimurium

The chloroform extracts at $5 \mathrm{mg} / 100 \mu \mathrm{L}$ showed less activity. But, as the concentration increases the bactericidal activity was increased. The extracts showed more activity at $40 \mathrm{mg} / 100 \mu \mathrm{L}$.

Among two plants S. officinalis showed more antibacterial activity. In these, methanol extracts of two plants more competent results along with ciprofloxacin on tested bacterial strains. The extracts also showed more activity on gram-negativeorganisms compared to gram-positiveorganisms. The extracts showed more activity on E. coli and S. typhimurium and lower activity on C. sporogenes and $S$. pneumoniae.

The results of the present study indicatethat the scientific evidence oftraditional use of selected medicinal plants in the treatment of different illnesses. To our knowledge, this is the first time reporting the antibacterial activity of the root parts of the Saponaria officinalis and Z. aramatum. Results could be point outthat the extracts showed the comparable antibacterial activity along with the standard drug ciprofloxacin. Therefore, the selected plants extracts could be used for bacterial infections, and their mechanism of action was unknown. The selected plants extracts showed the antibacterial activity moderately compared to ciprofloxacin, which inhibits the bacterial growth by inhibiting the replication process in them (Gootz et al., 1990). Current results also supports the cytotoxicity of selected plants extracts against bacterial cells were may be associated with same as ciprofloxacin or the mechanism of action may vary. So, the study of the mechanism of action of selected plants on their bactericidal activity may be useful. In recent times, the microorganisms becoming resistant (Stuart B. Levy, 2002; Lee Ventola, 2015) to the drugs because of their excess usage and changes in the environmental conditions (Philips, 1983).

\section{Acknowledgments}

The authors are thankful to authorities of AU College of Pharmaceutical Sciences, Andhra University for providing the necessary facilities and RGNF Fellowship, UGC for their financial support for doing the research work.

\section{References}

[1] Aminov RI. (2009). the role of antibiotics and antibiotic resistance in nature. Environ Microbiol, 11: 2970 2988.https://doi.org/10.1111/j.1462-2920.2009.01972.x.

[2] AminovRustam I. (2010). A Brief History of the Antibiotic Era: Lessons Learned and Challenges for the Future. Front Microbiol, 1: 134.https://doi.org/10.3389/fmicb.2010.00134.

[3] C. Lee Ventola, MS. (2015). The Antibiotic Resistance Crisis- Part 1: Causes and Threats. P T. 40(4): 277-283.

[4] Claudio Gualerzi O, Brandi Letizia, FabbrettiAttilio, Pon Cynthia L (2013). Antibiotics: Targets, Mechanisms and Resistance. John Wiley \& Sons. p1.

[5] Eliopoulos GM. (2004). Current and new antimicrobial agents. Am Heart J, 147(4): 587-92.https://doi.org/10.1016/j.ahj.2003.06.006.

[6] Ganga Rao, B. T. MallikarjunaRao, Y VenkateswaraRao. (2012). Anti-Bacterial Activity of Different extracts of MelochiacorchorifoliaandSpilanthesacmella aerial parts. Journal of Pharmacy Research (2012); 5 (6): 3022-3024.

[7] Gootz TD. (1990). Discovery and development of new antimicrobial agents. ClinMicrobiol Rev. 3(1): 1331.https://doi.org/10.1128/CMR.3.1.13.

[8] Gootz, TD, Barrett, JF, Sutcliffe, JA. (1990). Inhibitory effects of quinolone antibacterial agents on eucaryotic topoisomerases and related test systems. Antimicrob. Agents Chemother, 34: 812.https://doi.org/10.1128/AAC.34.1.8

[9] Habich D, Von Nussbaum F. (2006). Platensimycin, a new antibiotic and "superbug challenger" from nature. Chem Med Chem, 1: 951-954.https://doi.org/10.1002/cmdc.200600145.

[10] JaswantRai, GurpreetKaurRandhawa, and MandeepKaur. (2013). Recent advances in antibacterial drugs. Int J Appl Basic Med Res, 3(1): 3-10.https://doi.org/10.4103/2229-516X.112229.

[11] JatinSrivastava, Harish Chandra, Anant R Nautiyal, Swinder JS Kalra. (2014). Antimicrobial resistance (AMR) and plant-derived antimicrobials $\left(\mathrm{PDA}_{\mathrm{m}} \mathrm{s}\right)$ as an alternative drug line to control infections. 3 Biotech. 4(5): 451-460.

[12] Khare CP. 2007. Indian Medicinal Plants: An Illustrated Dictionary. Springer. ISBN: 978-0-387-70637.

[13] Negi JS, Bisht VK, Bhandari AK, Singh P, Sundriyal RC. (2011). Chemical Constituents and Biological Activities of the Genus Zanthoxylum: A Review. African Journal of Pure and Applied Chemistry, 5(12): 412-416.

[14] Phillips I. (1983). Environmental factors contributing to antibiotic resistance. Infect Control, $4 \quad$ (6):448 51.https://doi.org/10.1017/S0195941700058446. 
[15] Rajbhandari KR. 2001. Ethanobotany of Nepal, Ethano botanical Society olf Nepal, Khatmmandu. P. 189.

[16] Schelz Z, Hohmann J, Molnar J. (2010). Recent advances in research of antimicrobial effects of essential oils and plant derived compounds on bacteria. Ethnomedicine: A Source of Complementary Therapeutics, 179-201.

[17] Singh TP \& Singh OM. (2011). Phytochemical and Pharmacological Profile of Zanthoxylum armatum DC.-An Overview. Indian Journal of Natural Products and Resources, 2(3): 275-285.

[18] Stuart B. Levy. (2002). Factors impacting on the problem of antibiotic resistance. J Antimicrob Chemother, 49 (1): 25 30.https://doi.org/10.1093/jac/49.1.25.

[19] Sum PE \& Petersen P. (1999). Synthesis and structure-activity relationship of novel glycylcycline derivatives leading to the discovery of GAR-936. Bioorg Med ChemLett, 17; 9(10):1459-1462.

[20] Tan SY \&Tatsumura Y (2015). Alexander Fleming (1881-1955): Discoverer of penicillin. Singapore Medical Journal, 56(7): 366367. https://doi.org/10.11622/smedj.2015105.

[21] Wolff D, Witt T, Jurgens A, Gottsberger G. (2006). Nectar dynamics and reproductive success in Saponaria officinalis (Caryophyllaceae) in southern Germany. Flora. Morphologie, Geobotanik, Oekophysiologie. 201 (5): 353-364. 